Marquette University

e-Publications@Marquette

Electrical and Computer Engineering Faculty Electrical and Computer Engineering, Department

Research and Publications

$1-1-2013$

\title{
Rotor Bar Fault Monitoring Method Based on Analysis of Air-Gap Torques of Induction Motors
}

Aderiano da Silva

Marquette University, aderiano.dasilva@marquette.edu

Nabeel Demerdash

Marquette University, nabeel.demerdash@marquette.edu

Richard James Povinelli

Marquette University, richard.povinelli@marquette.edu

Accepted version. IEEE Transactions on Industrial Informatics, Vol. 9, No. 4 (November 2013): 2274-2283. DOI. (C) 2013 Institute of Electrical and Electronics Engineers (IEEE). Used with permission. 
NOT THE PUBLISHED VERSION; this is the author's final, peer-reviewed manuscript. The published version may be accessed by following the link in the citation at the bottom of the page.

\title{
Rotor Bar Fault Monitoring Method Based on Analysis of Air-Gap Torques of Induction Motors
}

\author{
Aderiano M. da Silva \\ Department of Mechanical Engineering, Marquette University \\ Milwaukee, $W I$ \\ Richard J. Povinelli \\ Electrical and Computer Engineering, Marquette University \\ Milwaukee, WI \\ Nabeel A.O. Demerdash \\ Electrical and Computer Engineering, Marquette University \\ Milwaukee, WI
}

\begin{abstract}
A robust method to monitor the operating conditions of induction motors is presented. This method utilizes the data analysis of the air-gap torque profile in conjunction with a Bayesian classifier to determine the operating condition of an induction motor as either healthy or faulty. This method is trained offline with datasets generated either from an induction motor modeled by a time-stepping finite-element (TSFE) method or experimental data. This method can effectively monitor the operating conditions of induction motors that are different in frame/class, ratings, or design from the motor used in the training stage. Such differences can include the level of load torque and operating frequency. This is due to a novel air-gap torque normalization method introduced here, which leads to a motor fault classification process independent of these parameters and with no need for prior information about the motor being monitored. The experimental results given in this paper validate the robustness and efficacy of this method. Additionally, this method relies exclusively on data analysis of motor terminal
\end{abstract}

IEEE Transactions on Industrial Informatics, Vol 9, No. 4 (November 2013): pg. 2274-2283. DOI. This article is (C) Institute of Electrical and Electronics Engineers (IEEE) and permission has been granted for this version to appear in e-Publications@Marquette. Institute of Electrical and Electronics Engineers (IEEE) does not grant permission for this article to be further copied/distributed or hosted elsewhere without the express permission from Institute of Electrical and Electronics Engineers (IEEE). 
NOT THE PUBLISHED VERSION; this is the author's final, peer-reviewed manuscript. The published version may be accessed by following the link in the citation at the bottom of the page.

operating voltages and currents, without relying on complex motor modeling or internal performance parameters not readily available.

\section{SECTION I.}

\section{Introduction}

Induction motors are complex electro-mechanical devices utilized worldwide as the main prime-movers in industrial applications for the conversion of power from electrical to mechanical form. Induction motors are highly reliable, require low maintenance, and have relatively high efficiency. However, such motors are susceptible to many types of faults in industrial applications. A motor failure that is not identified in an initial stage may become catastrophic to a process in which the motor is the prime-mover and the induction motor may suffer severe damage. Such motor faults are due to mechanical and electrical stresses. Mechanical stresses are caused by frequent starts and stops, overloads, and abrupt load changes, which can produce bearing faults and rotor bar breakages. Meanwhile, electrical stresses are usually associated with the power supply disturbances, frequent starts, and operation from PWM drives, which can cause inter-turn short circuits in stator winding turns/coils closest to the motor terminal, as well as broken rotor bars and bearing problems.

Several techniques have been proposed over the years to detect such motor faults. ${ }^{1-}$ 2,3,4,5,6,7,8,9,10,11,12,13,14 A widely studied method for motor fault detection is frequency spectrum analysis. $4,6-7,8,9,11,13 \mathrm{In}, 5$ the effect of broken bars on the air-gap torque was used as a fault indicator. However, manual investigation of the torque profile was needed to classify the motor as healthy or faulty. In, ${ }^{12}$ an online method to detect broken bars based on comparisons of torques from a current and a voltage model was presented. However, this method requires rotor inductance and rotor resistance that are not readily available and can vary with temperature. The rotor position also needed to be measured by an encoder, which is not part of many induction motor applications. Additionally, the motor needed to be subjected to a set of acceleration cycles which is not a practical task for online motor fault monitoring.

In, ${ }^{13}$ a comparison of motor fault monitoring methods including PSA of one phase current, instantaneous power, and torque was provided. The data obtained from these methods were manually investigated to determine the motor operating condition. In, ${ }^{14}$ a broken bar monitoring method based on pattern recognition was presented. This method was used to detect faulty motors even at no-load condition. However, this method was 
tested with a 7-rotor bars/pole motor containing three broken bars. That is more than $40 \%$ of broken bars per pole. As discussed later in Section V, a higher percentage of broken bars per pole produce a corresponding higher disturbance in the stator currents of a faulty motor. Thus, significant current disturbance might be found for this particular motor even at no-load condition. Additionally, the method of ${ }^{14}$ requires a new set of system signatures for each motor.

To address these limitations, a robust induction motor fault monitoring technique based on data analysis of the air-gap torque profile in conjunction with a statistical classifier technique to classify the operating condition of an induction motor as either healthy or faulty is presented in this paper. This method consists of two stages: 1) an offline training stage and 2) an online monitoring stage. In the training stage, a signature for the faulty case and a signature for the healthy case are built from the air-gap torque signal obtained either from time-stepping finite-element (TSFE) simulations ${ }^{15,16}$ or experimental data. In the monitoring stage, the signature that represents the operating condition of the actual induction motor being monitored is constructed from the online torque signal obtained from a torque estimator. This online signature is compared with the signatures obtained during the training stage in order to identify the actual operating condition of the test motor as healthy or faulty. The signatures are Gaussian mixture models (GMM) obtained from the Reconstructed Phase Space (RPS) of the signals under investigation as described next. No prior information about the monitored motor is needed to classify the operating condition.

This is a one-time training method, i.e. once the two signatures from the training set are obtained, one to represent the healthy and one the faulty state, this method does not need further training even when used in monitoring of other motors. A novel torque normalization method allows these two signatures from the training set to be used in the monitoring of the operating conditions of other motors even at different levels of load torque, operating frequencies, and different design specifications, including frame/class and ratings, from the motor of the training set. Only motor parameters readily available are required for this trained method, and no mathematical models of induction motors are required. This method yields a complete solution, that is, it automatically acquires and computes signals, and identifies the motor state as faulty or healthy without human interpretation of the data. External or intrusive feedback devices such as torque transducers and vibration sensors are not needed. The motor is continuously monitored while in operation, with no need to stop or apply any signal to the motor. The method presented here is capable of detecting a single broken bar in a motor with as high a number 
of bars per pole as 18 , that is, it can detect the operating condition of a motor with less than $6 \%$ of broken bars per pole.

In Section II, torque and speed estimators used in the monitoring stage, GMM and RPS used to build signatures, as well as air-gap torque disturbances caused by broken rotor bars are discussed. In Section III, the overall method is detailed. In Section IV, the experimental verification of this monitoring method is presented. This is followed by discussion of the results and conclusions.

\section{SECTION II.}

\section{Background}

Here, the torque and speed estimators used in this monitoring method, and the GMM and RPS used to build signatures are described. In addition, a brief discussion of the effects of broken rotor bars on the torque profile of an induction motor is given.

\section{A. Air-Gap Torque Disturbances Due to Broken Rotor Bars}

Broken rotor bars in induction motors produce torque modulations in both amplitude and frequency. These fundamentals are used in the aforementioned torque normalization process, which is a core portion of the presented monitoring method.

The air-gap torque (also called developed torque) profile of a healthy induction motor is approximately constant as shown in Fig. 1(a) and (d) for a 5-hp motor under 75\% and $100 \%$ of the rated load, respectively. Meanwhile, the air-gap torque profiles of an induction motor with broken rotor bars is modulated in amplitude and frequency as shown in Fig. 1(b), (c), (e), and (f). 


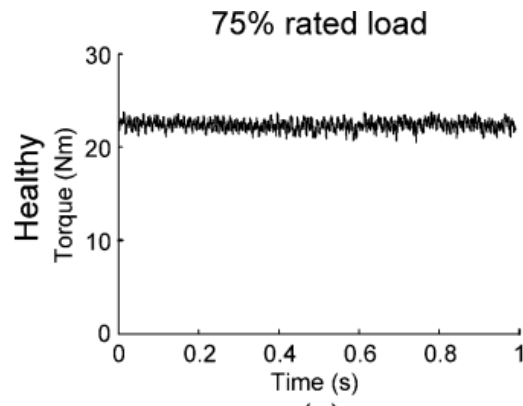

(a)

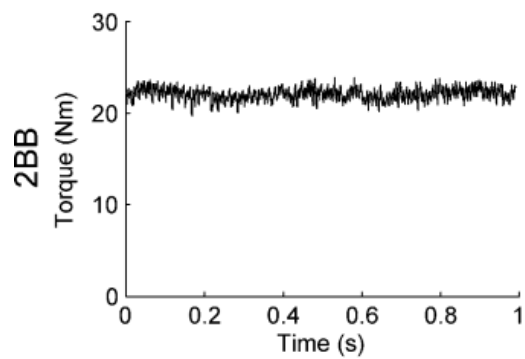

(b)

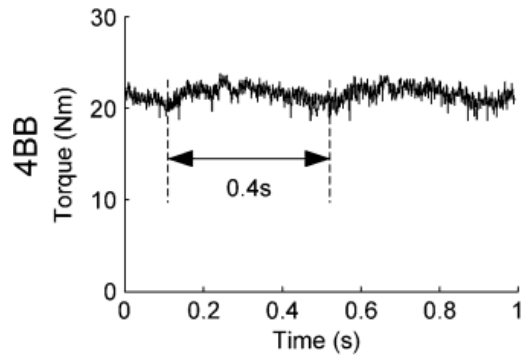

(c)

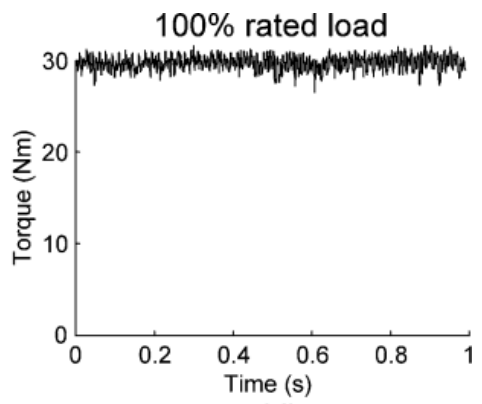

(d)

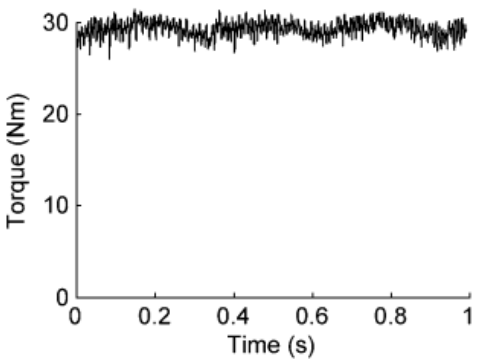

(e)

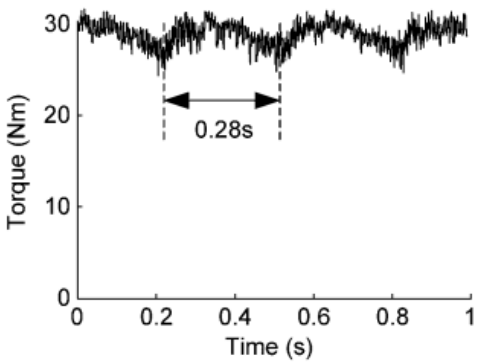

(f)

Fig. 1. Air-gap torque signal of a three-phase, 5-hp, six-pole, 60-Hz, 460-V, squirrel-cage induction motor. (a) $75 \%$ of rated torque under healthy condition at $1177 \mathrm{r} / \mathrm{min}$. (b) $75 \%$ of rated torque with two broken (2BB) bars at $1175 \mathrm{r} / \mathrm{min}$. (c) $75 \%$ of rated torque with four broken (4BB) bars at $1175 \mathrm{r} / \mathrm{min}$. (d)Full load under healthy condition at $1170 \mathrm{r} / \mathrm{min}$. (e) Full load with two broken bars at $1165 \mathrm{r} / \mathrm{min}$. (f) Full load with four broken bars at $1165 \mathrm{r} / \mathrm{min}$.

The amplitude of the torque modulation in a faulty motor is a function of the number of broken rotor bars and level of load torque. First, as the number of adjacent broken bars increases, the amplitude of the torque modulation also increases. The increase in the torque amplitude modulation with the number of adjacent broken bars can be observed in Fig. 1(b) and (c), which are for two broken bars and four broken bars, respectively, both at the same level of load torque, i.e. $75 \%$ of the rated torque. The same effect is also observed from Fig. 1(e) and (f), for two and four broken bars when the motor is operating at rated torque $(30 \mathrm{Nm})$. Second, an increase in the level of load torque yields an increase in the amplitude of torque modulation of a motor with broken bars. This effect can be observed by examination of Fig. 1(b) and (e) when the motor operates at $75 \%$ and

IEEE Transactions on Industrial Informatics, Vol 9, No. 4 (November 2013): pg. 2274-2283. DOI. This article is (C) Institute of Electrical and Electronics Engineers (IEEE) and permission has been granted for this version to appear in e-Publications@Marquette. Institute of Electrical and Electronics Engineers (IEEE) does not grant permission for this article to be further copied/distributed or hosted elsewhere without the express permission from Institute of Electrical and Electronics Engineers (IEEE). 
$100 \%$ of rated torque, respectively, both with two broken bars, and Fig. 1(c) and (f) when the motor operates at $75 \%$ and $100 \%$ of rated torque, respectively, both with four broken bars.

Meanwhile, the frequency of the torque profile modulation, which is $2 s f$, where $s$ is the slip and $f$ is the supply frequency, clearly depends on the supply frequency and the load torque. This load torque dependency is shown by comparison of Fig. 1(b) with Fig. 1(e), as well as Fig. 1(c) with Fig. 1(f). For instance, $2 s f$ for Fig. 1(c) with a rotor speed of $1175 \mathrm{r} / \mathrm{min}$ is $2\{[(1200-1175) \mathrm{r} / \mathrm{min}] /(1200 \mathrm{r} / \mathrm{min})]\} 60 \mathrm{~Hz}=2.5 \mathrm{~Hz}$, which means a period of $0.4 \mathrm{~s}$ as shown in this figure when the motor is at $75 \%$ of the rated torque. Meanwhile, $2 s f$ for Fig. 1(f) with a rotor speed of $1165 \mathrm{r} / \mathrm{min}$ is $2\{[(1200-$ $1165) \mathrm{r} / \mathrm{min}] /(1200 \mathrm{r} / \mathrm{min})]\} 60 \mathrm{~Hz}=3.5 \mathrm{~Hz}$, which means a period of $0.28 \mathrm{sec}$ as shown in this figure when the motor is operating at rated torque. Thus, the higher load torque in Fig. 1(f) resulted in a slower rotor speed, a larger slip frequency, and a shorter period of the torque profile modulation in comparison to Fig. 1(c).

IEEE Transactions on Industrial Informatics, Vol 9, No. 4 (November 2013): pg. 2274-2283. DOI. This article is C Institute of Electrical and Electronics Engineers (IEEE) and permission has been granted for this version to appear in e-Publications@Marquette. Institute of Electrical and Electronics Engineers (IEEE) does not grant permission for this article to be further copied/distributed or hosted elsewhere without the express permission from Institute of Electrical and Electronics Engineers (IEEE). 
NOT THE PUBLISHED VERSION; this is the author's final, peer-reviewed manuscript. The published version may be accessed by following the link in the citation at the bottom of the page.

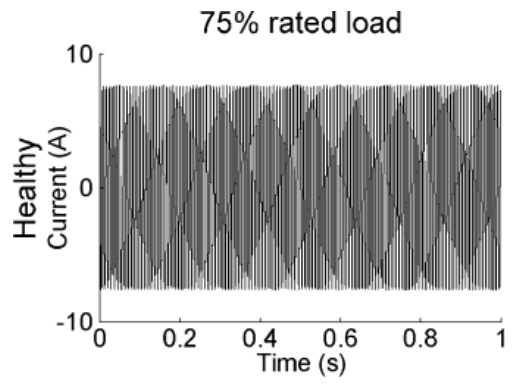

(a)

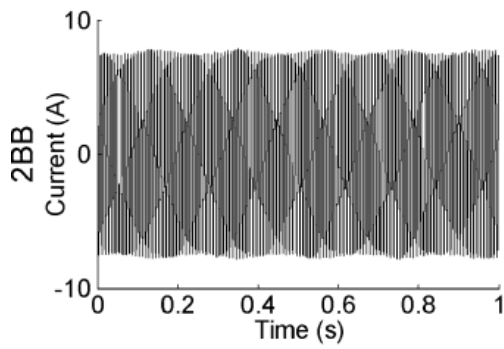

(b)

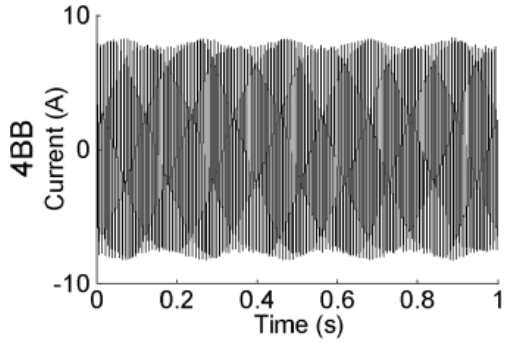

(c)

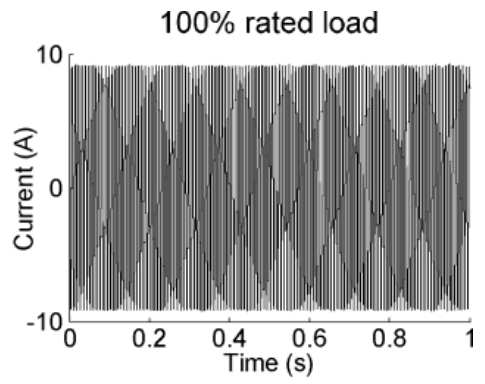

(d)

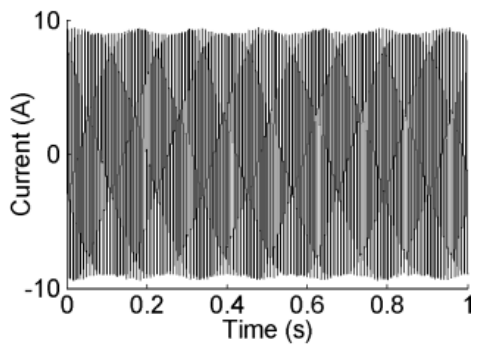

(e)

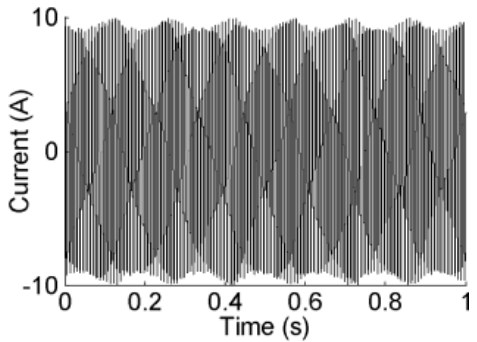

(f)

Fig. 2. Measured phase A current signal of a 3-phase, 5-hp, 6-pole, 60-Hz, 460-V, squirrel-cage induction motor. (a) $75 \%$ of rated torque under healthy condition at $1177 \mathrm{r} / \mathrm{min}$. (b) $75 \%$ of rated torque with two broken (2BB) bars at $1175 \mathrm{r} / \mathrm{min}$. (c) $75 \%$ of rated torque with four broken (4BB) bars at $1175 \mathrm{r} / \mathrm{min}$. (d) Full load under healthy condition at $1170 \mathrm{r} / \mathrm{min}$. (e) Full load with two broken bars at $1165 \mathrm{r} / \mathrm{min}$. (f) Full load with four broken bars at $1165 \mathrm{r} / \mathrm{min}$.

Additionally, the profile of the torque modulation is an intrinsic characteristic of an induction motor, and it does not change as its amplitude and frequency change.

Fig. 2 shows the experimentally measured phase A currents used to estimate the airgap torques illustrated in Fig. 1. Thus, the six cases of experimentally measured phase A currents shown in Fig. 2 correspond, respectively, to the six cases of estimated air-gap torques shown in Fig. 1.

IEEE Transactions on Industrial Informatics, Vol 9, No. 4 (November 2013): pg. 2274-2283. DOI. This article is (C) Institute of Electrical and Electronics Engineers (IEEE) and permission has been granted for this version to appear in e-Publications@Marquette. Institute of Electrical and Electronics Engineers (IEEE) does not grant permission for this article to be further copied/distributed or hosted elsewhere without the express permission from Institute of Electrical and Electronics Engineers (IEEE). 


\section{B. Air-Gap Torque Estimator}

Here, a well-known air-gap torque estimator $5,6,17,18$ based only on the three-phase stator terminal currents and voltages of an induction motor without need of any internal performance parameters is presented. This torque estimator is used during the monitoring stage to estimate the air-gap torque profile of the induction motor under fault monitoring. This is in order to generate a signature that represents its present operating condition that is used for the fault classification method discussed in Section III.

The derivation of this torque estimator is given in detail in. ${ }^{19}$ The air-gap (developed) torque $T$ is expressed as

$$
\begin{gathered}
T=\frac{p}{2 \sqrt{3}}\left\{\left(2 i_{a}+i_{c}\right) \int\left[v_{c a}-R\left(i_{c}-i_{a}\right)\right] d t\right. \\
\left.-\left(i_{c}+i_{a}\right) \int\left[v_{a b}-R\left(2 i_{a}-i_{c}\right)\right] d t\right\}
\end{gathered}
$$

in which only two voltage sensors and two current sensors are required to calculate the torque, where $p$ is the number of poles, $i_{a}, i_{b}$, and $i_{c}$ are the stator phase current, $v_{c a}$ and $v_{a b}$ are line-to-line stator voltages, and $R$ is the stator phase resistance. For a Y-connected induction motor, $R$ is half of the line-to-line resistance, $R_{L L}$, i.e., $R=R_{L L} / 2$ [5]. However, for a delta-connected induction motor, $R=3 R_{L L} / 2$. This equation yields the air-gap torque profile of an induction motor that is very close to the torque profile measured by a torque transducer with no significant drifting.

Furthermore, this torque estimator relies on both measured motor current and voltage signals, in which the voltage signals are integrated to yield the flux linkages. The flux linkages are a robust physical phenomenon that directly relate to the internal magnetic conditions in a motor's magnetic circuit and windings. Thus, the results of the torque estimator has the effect of both inputs (currents) and outputs (flux linkages and torque) of a motor which are closer to the physical condition inside a motor than the currents alone as used in. ${ }^{11,13}$

\section{Rotor Speed Estimator}

In this monitoring method, the rotor speed of the actual test motor is used to properly construct the online operating condition signatures. The rotor speed can be either measured via encoders or resolvers when available, or estimated. For the experimental results presented in this paper, the rotor speed was estimated with a well-known sensor- 
less method called rotor slot harmonics (RSH), because this approach is easily implementable and is relatively accurate..$^{20,21}$

\section{Reconstructed Phase Space}

The signatures of the presented monitoring methods are GMM obtained from the phase space reconstruction of the signals under investigation.

Using a signal generated by a system, phase space reconstruction creates a space equivalent, in the topological sense, to the original state space of a system. ${ }^{22,23}$ In this work, the signal is the air-gap torque, $T$. The matrix T represents the system dynamics in the RPS. Accordingly, the trajectory of the system dynamics is as follows:

$$
\mathbf{T}=\left[\begin{array}{cccc}
T_{1+(d-1) \tau} & \cdots & T_{1+\tau} & T_{1} \\
T_{2+(d-1) \tau} & \cdots & T_{2+\tau} & T_{2} \\
\vdots & \ddots & \vdots & \vdots \\
T_{N} & \cdots & T_{N-(d-2) \tau} & T_{N-(d-1) \tau}
\end{array}\right]
$$

where $T_{n}$ is the $n^{\text {th }}$ sample of the air-gap torque, $d$ is the dimension of the RPS, $\tau$ is time delay or lag from the present observation $T_{n} \cdot{ }^{23}$ The dimension $d$ is calculated using the false nearest neighborhood (FNN) technique. ${ }^{23-24,25}$ This technique counts the number of points in a RPS that are false nearest neighbors, i.e. the points in the RPS that are projected near to each other as opposed to being near because of the dynamics of the system. The count of false nearest neighbors is given as follows:

$$
\sum_{n=1+(d-1) \tau}^{N} \operatorname{sgn}\left(\frac{\left|D_{n}(d+1)^{2}-D_{n}(d)^{2}\right|}{D_{n}(d)}-r\right)
$$

where $D_{n}(d)$ is the distance between two points of the signal, $N$ is the total number of data points of the signal, and $r$ is a threshold. The number of false nearest neighbors is normalized by the total number of points in the RPS yielding the percentage of false nearest neighbors. This percentage is further compared with another threshold, which typically assumes values between 0.001 and 0.01 . This comparison yields the appropriated dimension of the RPS that represents the dynamics of the signal under investigation. 


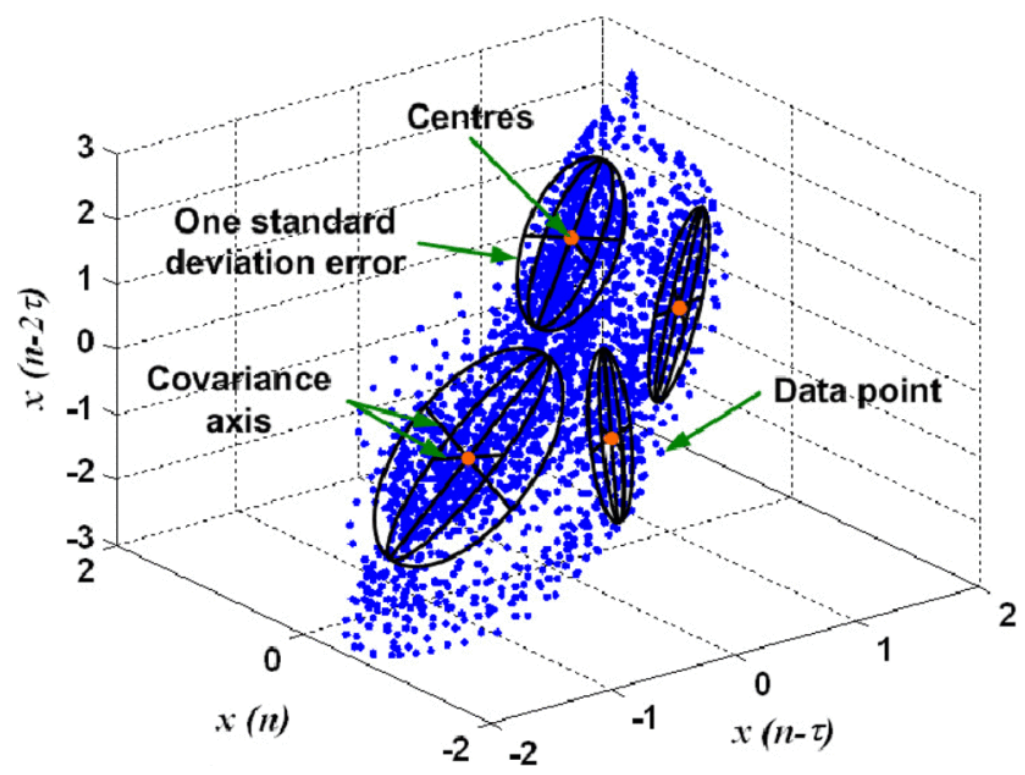

Fig. 3. RPS of healthy 2-hp motor with corresponding GMM with four mixtures.

The time lag $\tau$ is calculated using the automutual information function, $I(\tau)$, which is given as follows: 23,24

$$
I(\tau) \sum_{T_{n}, T_{n+\tau}} P\left(T_{n}, T_{n+\tau}\right) \ln \left(\frac{P\left(T_{n}, T_{n+\tau}\right)}{P\left(T_{n}\right) P\left(T_{n+\tau}\right)}\right)
$$

where $P\left(T_{n}, T_{n+\tau}\right)$ is the joint probability density for the signals $T_{n}$ and $T_{n+\tau}$, and $P\left(T_{n}\right)$ and $P\left(T_{n+\tau}\right)$ are, respectively, the probability densities for the signals $T_{n}$ and $T_{n+\tau}$, which are same the signal but delayed from each other by the time lag, $\tau$. The first minimum of (4) is chosen as the time delay used to reconstruct the phase space of the signal $T_{n}$.

Using the FNN technique on air gap torque of a healthy 2-hp induction motor signal yielded a dimension of three. Similarly, the automutual information approached yielded a time lag of five. The resulting RPS of this air-gap with $d=3$ and $\tau=5$ is shown is Fig. 3.

IEEE Transactions on Industrial Informatics, Vol 9, No. 4 (November 2013): pg. 2274-2283. DOI. This article is (C) Institute of Electrical and Electronics Engineers (IEEE) and permission has been granted for this version to appear in e-Publications@Marquette. Institute of Electrical and Electronics Engineers (IEEE) does not grant permission for this article to be further copied/distributed or hosted elsewhere without the express permission from Institute of Electrical and Electronics Engineers (IEEE). 


\section{Simulate induction motor using TSFE}

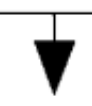

\section{Air-gap torque}

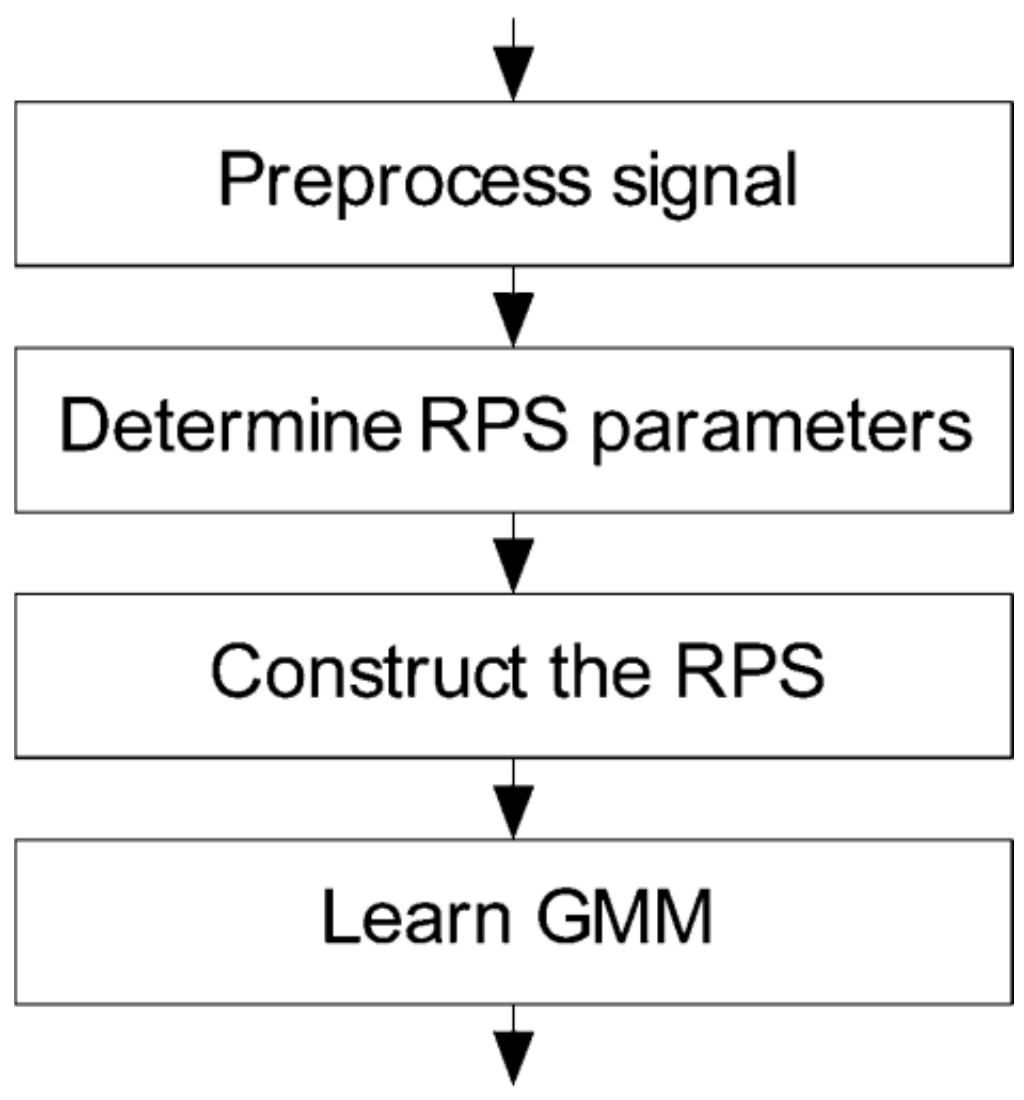

\section{GMM signatures, time lag and dimension}

Fig. 4. Offline motor fault signature learning algorithm.

A RPS is sampling frequency-dependent, i.e., if the same signal is acquired with different sampling frequencies, and the same time lag and dimension is used to build the RPS for both signals, the resulting trajectories in the RPSs are not the same. Thus, signal classification approaches based on RPS must perform sampling frequency normalization.

IEEE Transactions on Industrial Informatics, Vol 9, No. 4 (November 2013): pg. 2274-2283. DOI. This article is @ Institute of Electrical and Electronics Engineers (IEEE) and permission has been granted for this version to appear in e-Publications@Marquette. Institute of Electrical and Electronics Engineers (IEEE) does not grant permission for this article to be further copied/distributed or hosted elsewhere without the express permission from Institute of Electrical and Electronics Engineers (IEEE). 


\section{E. Gaussian Mixture Models}

A GMM is an approach used for density estimation. ${ }^{26} \mathrm{~A}$ GMM with $M$ mixtures is defined as follows:

$$
p(\mathbf{x})=\sum_{m=1}^{M} w_{m} p_{m}(x)=\sum_{m=1}^{M} w_{m} N\left(\mathbf{x} ; \mu_{m}, \Sigma_{m}\right)
$$

where $M$ is the number of mixtures of a model, $w_{m}$ is the mixture weight, $p_{m}(x)$ is the density function of the model, $\mathbf{x}$ is a Gaussian random variable with a probability density function $p_{m}(x), N\left(\mathbf{x} ; \mu_{m}, \Sigma_{m}\right)$ is a normal distribution with mean value $\mu_{m}$, and covariance $\Sigma_{m}$ of the Gaussian density function of each mixture $M$ of the GMM. The constraints of $w_{m}$ are $\sum w_{m}=1$, with $m=1, \ldots, M$ and $0 \leq w_{m} \leq 1$. A GMM over an RPS is shown in Fig. 3 . This figure shows the data points and three GMM parameters estimated by an expectation maximization (EM) algorithm:27 centers, covariance axes, and one standard deviation error for each mixture.

In the presented monitoring method, the reconstructed phase space was used to build the Gaussian mixture model (signature) for each motor operating condition.

\section{SECTION III.}

\section{Method}

The monitoring method presented in this paper classifies the motor operating condition of an induction motor as either healthy or faulty based on the data analysis of the air-gap torque profile. A faulty condition represents any number of adjacent broken rotor bars.

The high-level algorithm of the monitoring method is depicted in Fig. 4 and Fig. 6. The proposed approach is divided in two stages: the training (offline) stage and the monitoring (online) stage. 


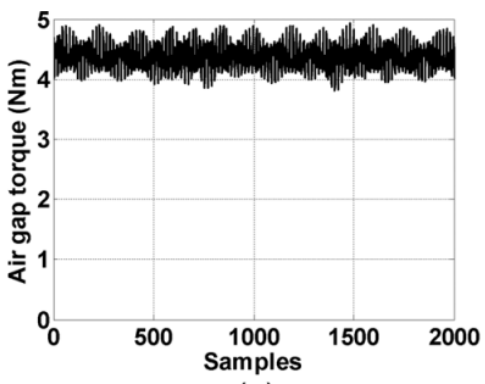

(a)

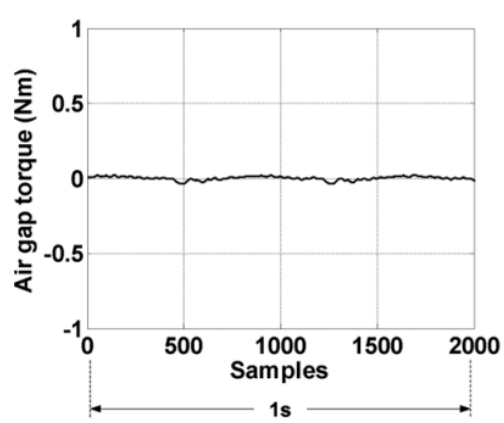

(c)

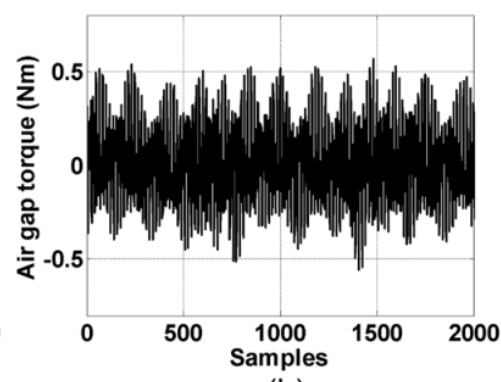

(b)

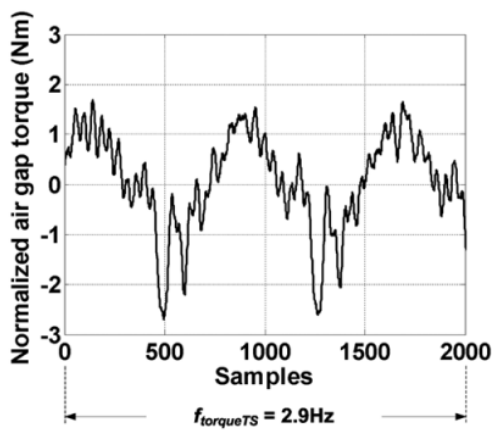

(d)

Fig. 5. Training stage air-gap torque profiles (signals) for the simulated 2-hp motor. (a) MAGSOFT simulation. (b) With dc offset removed. (c) Low pass filtered. (d) Final normalized torque signal.

\section{A. Training Stage}

During the training stage, this method generates signatures for a healthy and faulty three-phase, 2-hp, two-pole, 60-Hz, 460-V, squirrel-cage induction motor simulated in Flux2D-MAGSOFT TSFE software at rated load and speed. ${ }^{16,28}$ These signatures are generated from the air-gap torque profile of the healthy and faulty operating condition obtained directly from the simulations at a sampling frequency of $2 \mathrm{kHz}$. Here, the faulty condition is that of a motor with one broken rotor bar. Experimental data can be used instead of simulation data in this training stage. The algorithm of the training stage contains five steps as illustrated in Fig. 4.

In the first step, MAGSOFT generates time-domain profiles of the air-gap torque signals for the healthy and faulty cases. One second of the air-gap torque profile (signal) for the one broken bar case is shown in Fig. 5(a).

The second step is the preprocessing of the torque signal. In this step, the torque signal is normalized to allow the resulting signatures from the training stage to be used on the fault monitoring of different induction motors. This preprocessing step also removes the high frequency components of the torque signal and normalizes it. To minimize filtering errors, the dc offset is eliminated as shown in Fig. 5(b). The torque signal is filtered by a 
sixth-order low-pass elliptic digital filter with a cutoff frequency of $100 \mathrm{~Hz}$, a passband of $0.1 \mathrm{~dB}$, and a stopband of $50 \mathrm{~dB} .^{29}$ The resulting filtered signal is shown in Fig. 5(c). Finally, the torque signal is normalized to zero mean and unit standard deviation. An example of the normalized air-gap torque signal is shown in Fig. 5(d).

The third step is determine the RPS dimension, $d$, and the time lag, $\tau$, using the FNN and automutual information techniques, respectively. The FNN and automutual information methods are described above in Section II-D.

The fourth step generates RPSs according to (2). One RPS is constructed from the torque signal of the healthy simulated motor. A second RPS is constructed from the torque signal of the simulated motor with one broken bar.

The fifth and last step learns the GMM signatures. This step consists of constructing a Gaussian mixtures model (GMM) 22,26 from each of the RPSs. The resulting models are the signatures of each motor operating condition. Thus, this method builds one GMM for the healthy case and one GMM for the faulty case.

The number of mixtures is determined empirically by analyzing training set accuracy across a range of number of mixtures. ${ }^{1}$ The classification accuracy tends toward an asymptote as the number of mixtures increase. Thus, the lowest number of mixtures that yields the highest accuracy for a given training set is chosen and this number become a constant in this monitoring method even for monitoring of motors different from the one used in the training stage. This approach yielded four mixtures as the best for the proposed monitoring method.

Meanwhile, a reference frequency for the torque normalization process of the monitoring (testing) stage is calculated, see Fig. 5(d). The reference frequency is the frequency of the filtered and normalized air-gap torque, $f_{\text {torqueTs, }}$ which is given as follows:

$$
f_{\text {torqueTS }}=2 s_{\mathrm{TS}} f_{\mathrm{TS}}
$$

where $s_{\mathrm{TS}}$ is the slip and $f_{T S}$ is the operating frequency of the motor used in the training stage. The frequency $f_{T S}$ as well as the synchronous and the rotor speeds used to calculate the slip $s_{\text {TS }}$ are readily obtained from MAGSOFT software. The simulated faulty motor with rotor speed of $3511 \mathrm{r} / \mathrm{min}$, yielded a normalized torque frequency $f_{\text {torqueTs }}$, equal to 2.96 
NOT THE PUBLISHED VERSION; this is the author's final, peer-reviewed manuscript. The published version may be accessed by following the link in the citation at the bottom of the page.

Hz as shown in Fig. 5(d). This normalized torque frequency $f_{\text {torqueTs, }}$ is used during the monitoring stage as shown next.

\section{B. Monitoring Stage}

The monitoring (testing) stage, illustrated in Fig. 6, uses datasets experimentally acquired from actual induction motors and can be divided into the following steps described below.

First, the air-gap torque and rotor speed are estimated from the acquired voltage and current signals of the actual test motor. The air-gap torque is computed using a torque estimator according to (1) of Section II-B. A resulting estimated air-gap torque signal is illustrated in Fig. 7(a) for the 5-hp motor at rated speed and full load with four broken bars.

Next, segments of one second of the torque signal are preprocessed using the same approach used during the training stage, i.e. dc offset elimination, low pass filtering, and zero mean and unit standard deviation normalization. This normalizes the amplitude of the torque signal. The resulting signals are illustrated in Fig. 7(b) with the dc offset removed and Fig. 7(c) with filtered and amplitude normalized torque signal for the 5-hp motor.

Third, a frequency normalization process is performed on the torque signal. The frequency of the fundamental component of the air-gap torque for the test motor, $f_{\text {torquems }}$, is given as follows:

\section{$f_{\text {torqueMS }}=2 s_{\mathrm{MS}} f_{\mathrm{MS}}$}

where $s_{\mathrm{MS}}$ is the slip and $f_{\mathrm{MS}}$ is the operating frequency of the test motor. The operating frequency $f_{\mathrm{MS}}$ and the rotor speed $n$ of the actual monitored motor are computed by the speed estimator given in Section II-C. The slip $s_{\mathrm{MS}}$ is calculated as $s_{\mathrm{MS}}=\left(n_{\text {syn }}-n\right) / n_{\text {syn }}$, where $n_{\text {syn }}$ is the synchronous motor speed. The $n_{\text {syn }}$ is calculated as $n_{\text {syn }}=120 \times f_{\mathrm{Ms}} / p$, where $p$ is the number of poles of the motor. According to (7), for the aforementioned 5-hp, four-pole induction motor with a rotor speed $n$ of $1165 \mathrm{r} / \mathrm{min}$, the frequency of the torque profile $f_{\text {torquems }}$ is $3.5 \mathrm{~Hz}$, as shown in Fig. 7(a) and (b) and Section II-A above. The frequency normalization ratio $f_{\text {ratio }}$ of the torque signal obtained for the real test motor is computed as follows: 
NOT THE PUBLISHED VERSION; this is the author's final, peer-reviewed manuscript. The published version may be accessed by following the link in the citation at the bottom of the page.

$$
f_{\text {ratio }}=\frac{f_{\text {torqueTs }}}{f_{\text {torqueMs }}}
$$

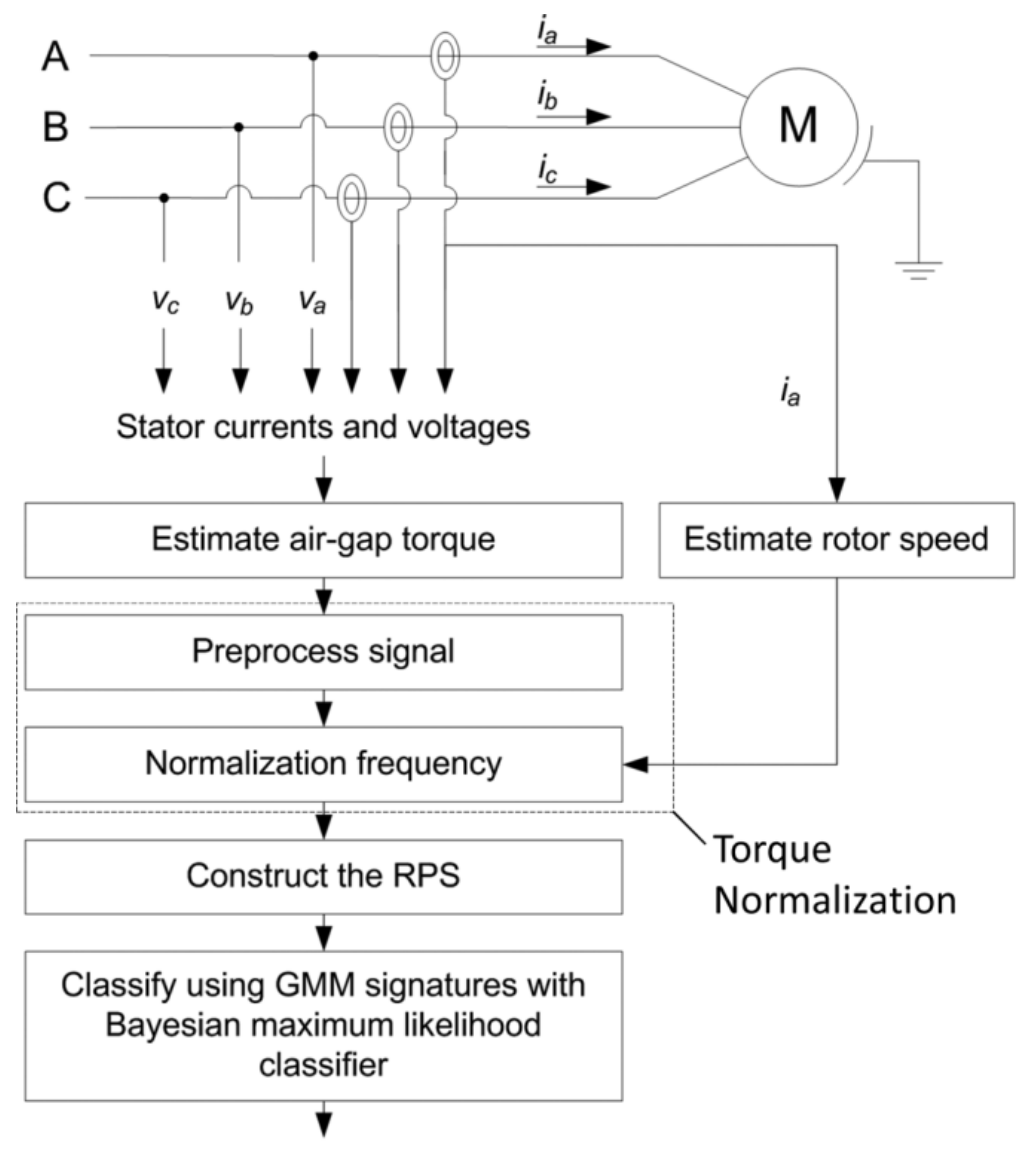

Motor operating condition: healthy or faulty

Fig. 6. Online motor fault monitoring algorithm.

IEEE Transactions on Industrial Informatics, Vol 9, No. 4 (November 2013): pg. 2274-2283. DOI. This article is (C) Institute of Electrical and Electronics Engineers (IEEE) and permission has been granted for this version to appear in e-Publications@Marquette. Institute of Electrical and Electronics Engineers (IEEE) does not grant permission for this article to be further copied/distributed or hosted elsewhere without the express permission from Institute of Electrical and Electronics Engineers (IEEE). 
NOT THE PUBLISHED VERSION; this is the author's final, peer-reviewed manuscript. The published version may be accessed by following the link in the citation at the bottom of the page.

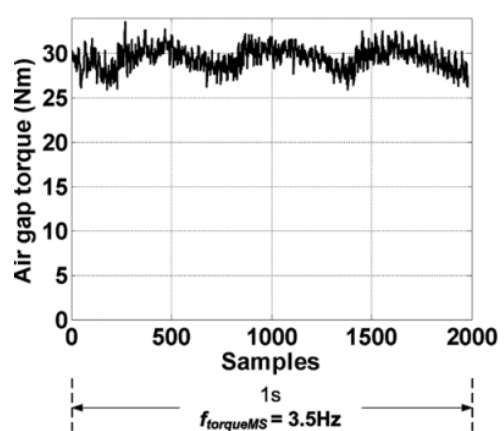

(a)

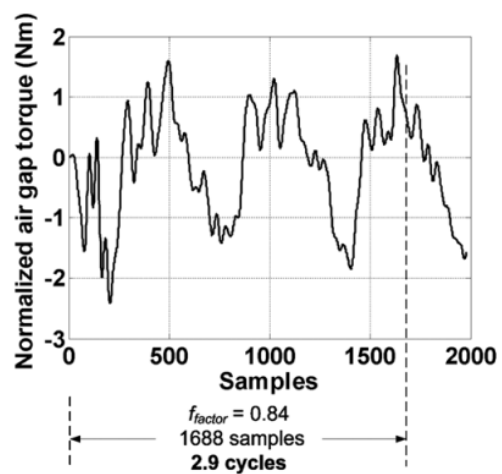

(c)

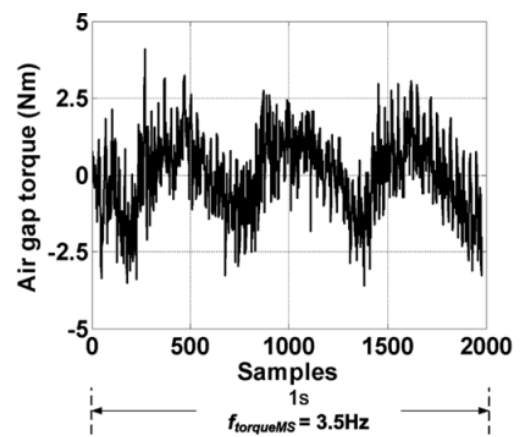

(b)

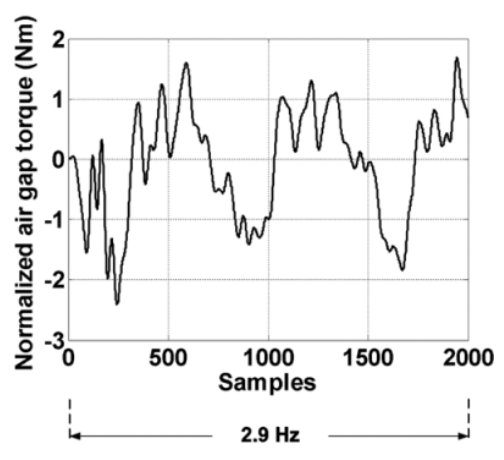

(d)

Fig. 7. Monitoring (testing) stage air-gap torque profiles (signals) for the 5 -hp motor at rated speed and rated load. (a) From torque estimator. (b) With dc offset removed. (c) Filtered by a low-pass filter and with amplitude normalization. (d)Final amplitude and frequency normalized torque signal.

Accordingly, the $f_{\text {ratio }}=2.96 \mathrm{~Hz} / 3.5 \mathrm{~Hz}=0.84$ for the TSFE simulated 2-hp motor and the 5-hp actual test motor, respectively [see Fig. 7(c)].

Using frequency normalization ratio $f_{\text {ratio }}$, the test motor torque signal is frequency normalized such that its fundamental frequency component is equivalent to that used during the training stage. This is accomplished as follows:

1. $f_{\text {ratio }}<1$. First, the number of data points of each sample of the testing set, which is 2000 in Fig. 7(c), is multiplied by the $f_{\text {ratio }}$. Second, the torque signal is truncated at this resulting number of samples and the remainder portion of the signal is discharged. Next, the truncated torque signal is up sampled by a factor $\mathrm{L}=$ $1000 / f_{\text {ratio }}$ and down sampled by a factor $M=1000^{29}$ in order to obtain the truncated signal with the original number of data samples as shown in Fig. 7(d) and, consequently, with the same frequency of the torque signal of the training set.

2. $f_{\text {ratio }}>1$. The torque signal of the testing set is simply up-sampled by a factor $\mathrm{L}=$ $1000 / f_{\text {ratio }}$ and down-sampled by a factor $\mathrm{M}=1000$. If $f_{\text {ratio }}=1$, the frequency normalization process is skipped.

IEEE Transactions on Industrial Informatics, Vol 9, No. 4 (November 2013): pg. 2274-2283. DOI. This article is (C Institute of Electrical and Electronics Engineers (IEEE) and permission has been granted for this version to appear in e-Publications@Marquette. Institute of Electrical and Electronics Engineers (IEEE) does not grant permission for this article to be further copied/distributed or hosted elsewhere without the express permission from Institute of Electrical and Electronics Engineers (IEEE). 
The up and down-sampling factors were 1000 in order to minimize resampling error, which is usually less than two data points for a torque signal with 2000 points. Thus, the resampling error does not cause any significant degradation in motor fault classification accuracy.

This match in the fundamental frequency component of the training and testing dataset after frequency normalization occurs only if the torque modulation of the testing and training sets is due to broken rotor bars. This match in frequency is needed to improve the motor fault monitoring accuracy since the RPS used to generate the signatures may yield signatures for the same motor operating condition that do not match and cause misclassifications.

As shown earlier in Section II, the frequency of the torque profile modulation due to broken rotor bars is a function of the operating frequency and the level of the motor torque. Thus, this adjustment in frequency of the torque modulation signal physically corresponds to the motor operation at different power frequencies or levels of load, and not a function of the motor status of operation under faulty or healthy conditions. Accordingly, this frequency normalization of the torque signal yields a motor fault monitoring method which is independent of the level of load torque, operating frequency, or design specifications, such as power rating and number of poles, which may be different from the TSFE-simulated motor being used in the training stage. This normalization in amplitude and frequency constitutes the proposed torque normalization method.

Fourth, a RPS from the normalized torque signal is constructed according to (2) using the time lag $\tau$ and dimension $d$, for the training stage.

The final step is fault classification, in which the conditional likelihoods of the RPS obtained during the monitoring stage and the GMM signatures generated during the training stage are computed as follows:

$$
p\left(\mathbf{T} \mid c_{i}\right)=\prod_{n=\mathbf{1}+(d-\mathbf{1}) \tau}^{N} p\left(\mathbf{T}_{n} \mid c_{i}\right)
$$

where T is the RPS matrix, $d$ is the dimension of the RPS, $\tau$ is the time lag of the RPS, $\mathbf{T}_{n}$ is a row of the RPS matrix, $N$ is the number of sampled data points of the torque signal, and $p\left(\mathbf{T}_{n} \mid c_{i}\right)$ is the conditional probability of $\mathbf{T}_{n}$ belonging to a class $c_{i}$. A Bayesian maximum- 
likelihood classifier is used to identify the signature from the training stage with maximum likelihood $\hat{c}^{22}$ as

$$
\hat{c}=\arg \operatorname{maxp}\left(\mathbf{X} \mid c_{i}\right)
$$

This classifies motor operating condition as healthy or faulty. The experimental verification of this method is given next.

\section{SECTION IV.}

\section{Experimental Verification of the Method}

The proposed monitoring method was validated using two physical induction motors. These namely are a three-phase, 2-hp, two-pole, 60-Hz, 24 stator slots, 36 rotor bars, squirrel-cage induction motor line energized from a constant frequency $230 \mathrm{~V}$ sinusoidal power supply, and a three-phase, 5-hp, six-pole, $60 \mathrm{~Hz}, 36$ stator slots, 45 rotor bars, squirrel-cage induction motor, line energized from constant frequency $460-\mathrm{V}$ sinusoidal power supply.

The 2-hp motor was tested under three different levels of load (50\%, 75\%, and $100 \%$ ) and four fault conditions (healthy, one broken bar, three broken bars, and five broken bars). Thus, the 2-hp motor was tested under 12 different operating conditions. For each operating condition, nine datasets were collected and tested for a total 108 datasets.

The 5-hp motor was tested under three different levels of load (50\%, 75\%, and $100 \%$ ) and under five fault conditions (healthy, one broken bar, two broken bars, three broken bars, and four broken bars). Thus, the 5-hp motor was tested under 15 different operating conditions. For each operating condition, five datasets were collected and tested for a total 75 datasets.

In the laboratory, the testing was conducted in the following manner for both 2-hp and 5-hp motors to obtain the testing datasets. The induction motor under test was mounted in a dynamometer configuration, where the shaft of the induction motor was directly coupled to the shaft of a dc motor, which acted as the load. The dc motor was controlled by a dc drive that was set in torque mode, allowing the load (torque) applied to the testing motor to be controlled. The fault conditions were progressively created by drilling holes in the rotor bars. 
The algorithm of this monitoring method was trained with data from a 2-hp, twopole, $60-\mathrm{Hz}, 36$ rotor bars, squirrel-cage induction motor simulated using MAGSOFT as a TSFE method [16] for two operating conditions (healthy and one broken bar). The training set was composed of two time series for the healthy case and two additional time series for the faulty case. Each time series was generated at a sampling frequency of $2 \mathrm{kHz}$. Thus, each time series of one second contains 2000 sampled data points.

Table I Motor Fault Monitoring Accuracy for a Three-Phase, 2-hp, Two-Pole, 60-Hz Induction Motors at a Frequency of $60 \mathrm{~Hz}$ and Motor Loads of $50 \%, 75 \%$, and $100 \%$ of the Rated Torque

\begin{tabular}{|l|c|c|c|}
\hline \multirow{2}{*}{ 2-hp Induction Motor } & \multicolumn{3}{|c|}{ Motor load as \% of Rated Torque } \\
& $50 \%$ & $75 \%$ & $100 \%$ \\
\hline Accuracy (\%) & 83 & 75 & 100 \\
\hline Standard Deviation & 0.36 & 0.44 & 0.00 \\
\hline Sensitivity & 85 & 74 & 100 \\
\hline Specificity & 78 & 78 & 100 \\
\hline
\end{tabular}

Table II Motor Fault Monitoring Accuracy for a Three-Phase, 5-hp, Six-Pole, 60-Hz Induction Motors at a Frequency of $60 \mathrm{~Hz}$ and Motor Loads of $50 \%, 75 \%$, and $100 \%$ of the Rated Torque

\begin{tabular}{|l|c|c|c|}
\hline \multirow{2}{*}{ 5-hp Induction Motor } & \multicolumn{3}{|c|}{ Motor load as \% of Rated Torque } \\
& $50 \%$ & $75 \%$ & $100 \%$ \\
\hline Accuracy (\%) & 92 & 100 & 100 \\
\hline Standard Deviation & 0.2 & 0 & 0 \\
\hline Sensitivity (\%) & 95 & 100 & 100 \\
\hline Specificity (\%) & 80 & 100 & 100 \\
\hline
\end{tabular}

The experimental results for this rotor bar fault monitoring method are presented in Tables I and II, respectively, for the 2-hp and 5-hp motors. From these tables, one can observe that the method presented in this paper yielded a perfect fault monitoring accuracy of $100 \%$ at rated torque for both motors. Also, as the level of motor load decreases the accuracy also decreases, because the signatures are based on the ac component of the torque signals, which is load dependent as discussed earlier in Section II. As also shown in Table II, an accuracy of $92 \%$ was obtained for the 5 -hp motor at $50 \%$ of rated torque, which means two misclassifications out of 25. Meanwhile, an accuracy of $83 \%$ was obtained at $50 \%$ of rated torque for the 2-hp motor as shown in Table I, which represents six misclassifications out of 36.

Furthermore, a fault monitoring accuracy of $100 \%$ was obtained for the 5 -hp motor at $75 \%$ of rated torque while an accuracy of $75 \%$ was obtained at $75 \%$ of the rated load for the 2-hp motor, which represents nine misclassifications out of 36 . The accuracy evidenced by these results validates the efficacy of this monitoring method.

IEEE Transactions on Industrial Informatics, Vol 9, No. 4 (November 2013): pg. 2274-2283. DOI. This article is (C) Institute of Electrical and Electronics Engineers (IEEE) and permission has been granted for this version to appear in e-Publications@Marquette. Institute of Electrical and Electronics Engineers (IEEE) does not grant permission for this article to be further copied/distributed or hosted elsewhere without the express permission from Institute of Electrical and Electronics Engineers (IEEE). 
NOT THE PUBLISHED VERSION; this is the author's final, peer-reviewed manuscript. The published version may be accessed by following the link in the citation at the bottom of the page.

\section{SECTION V.}

\section{Discussion of Results}

The broken rotor bar monitoring method presented here is robust in that the fault signatures generated from a simulation of a specific machine can be used to classify faults in motors with different power ratings, numbers of poles, levels of load torque, operating frequencies, and other design specifications. In this case, the signatures for the training stage were generated from a simulated 2-hp induction machine and applied in the fault monitoring of a physical 2-hp and a 5-hp induction motor.

The main goal of this fault monitoring method is to classify the operating condition of an induction motor as healthy or faulty without accounting for the exact number of broken bars, which improves the robustness of this method. Again, the faulty condition here means any number of broken rotor bars.

\section{A. Required Sensors}

This method uses only the three phase stator currents and voltages to classify a motor as healthy or faulty. Such variables are usually monitored or readily available in many applications, in which case extra sensors and installations are not required. In this method, the torque and speed signals which are used to generate the signatures during the monitoring stages are obtainable here through torque and speed estimators, respectively, without need for direct torque or speed measurement. Accordingly, the torque estimator uses the three phase stator currents and voltages in addition to parameters that are easily obtainable from data normally listed in the nameplates of such induction motors, while the speed estimator uses only one stator phase current, and induction motor parameters that are also easily available from the nameplate data. Parameter estimation has been successfully demonstrated in sensor failure detection and mitigation ${ }^{30}$ even under noise conditions. ${ }^{31}$

\section{B. Amplitude and Frequency Normalization of Torque}

The results shown in Tables I and II validate the efficacy of the monitoring method in classifying the operating conditions of induction motors with different specifications and operating setups (frequency and level of load) from the motor used to train this method. This was made possible through the use of a novel torque normalization process, which yields a torque signal from a real motor with fundamental frequency component and 
amplitude almost identical to the torque signal generated by simulation for the training stage when the training and testing sets consist of broken bar cases. The amplitude of the torque signal modulation due to broken bar faults is a function of the motor load, motor power, and the number of broken bars as shown in Section II. Thus, the normalization in amplitude renders signatures which are independent of these parameters. However, the profile of the torque modulation remains the same in amplitude during normalization. On the other hand, the frequency of the torque modulations due to broken bar faults is a function of the level of load torque and operating frequency. Accordingly, the torque normalization process continuously adjusts the frequency of the torque signal of the testing set in such a manner that if the signals from the training and testing sets are due to broken bars, there will be a match in frequency between both signals. These frequency and amplitude normalizations are necessary. This is because the reconstructed phase space used to build the Gaussian mixture models (signatures) of the operating conditions during the training and testing stages is sensitive to the amplitude, frequency, and profile of the signals. Thus, the torque normalization process under broken bar fault condition yields a match in amplitude and frequency between the torque signals of the training and testing sets. This is while the torque profile, which is an inherent characteristic of broken bar faults, remains in its original form. Thus, this match in amplitude, frequency, and profile between training and testing sets for fault conditions is crucial to the process of obtaining a high level of fault classification accuracy due to the RPS sampling frequency dependency. Thus, the amplitude and frequency normalization does not imply losses of information regarding the operating condition of the motor.

\section{Effect of Light Load to the Fault Classification Accuracy}

In Tables I and II, it is shown that at light loads the motor fault classification accuracy decreases. This can be explained from an electric machinery theory and magnetic field viewpoint. From an electric machinery viewpoint, the rotor electric circuit impedance increases at light loads and approaches the no-load rotor impedance, which is approximately an open-circuit condition. Thus, any failure in the rotor cage, such as broken rotor bars, is reflected with a weak effect in the stator winding circuit and consequently results in a small disturbance in the stator currents and air-gap torque, which in turn gives rise to the difficulties in classifying the correct status of motor health. Now, from a magnetic field viewpoint, for a healthy rotor cage the rotor core remains at a good degree of circular magnetic symmetry at rated load or near rated load. However, when a rotor bar breaks at rated load or close to it, this symmetry is lost and a local saturation, causing lower lamination permeabilities, at that spot where the broken bar or bars are located. This results is an "apparent magnetic saliency or asymmetry" in the rotor. This asymmetry, 
which rotates at the slip speed with respect the synchronously rotating air-gap flux, disturbs the stator currents and consequently the air-gap torque. Accordingly, this effect is weakened at light loads, and hence this gives rise to the difficulty in diagnosing the status of rotor health for the 2-hp and 5-hp case-study motors at these light loads. This also explains why loads below $50 \%$ of the rated load were not considered in this work. Additionally, induction motors are expected to work close to rated torque in order to obtain higher efficiency. Even in applications in which the motor is lightly loaded, the motor is expected to momentarily operate above $50 \%$ of the rated load when the fault detection can occur.

\section{Comparison of Accuracy Between the 2-hp and 5-hp Motors}

Tables I and II show that this method yields a better accuracy for the 5-hp motor than the 2-hp motor. This is because the number of rotor bars per pole for the 2-hp motor is 18 rotor bars/pole (36 bars/2 poles), while the number of rotor bars per pole was 7.5 for the 5 -hp motor (45 bars/6 poles). Thus, one bar breakage in the 2-hp motor is a much lesser disturbance to the magnetic field of the air-gap torque signal than it is in the 5-hp motor case. Hence, the capability to detect broken rotor bars in this 2-hp motor is reduced in comparison to that capability of the 5-hp motor case.

\section{E. Signatures from Torque Versus Current}

The air-gap torque is modulated with a characteristic profile at $2 s f$ main frequency component for a faulty case. On the other hand, a $2 s f$ frequency component slightly modulates the main frequency component of a current signal in a faulty case. Thus, the RPS from current signals would be very similar for a faulty and healthy case and difficult to identify. Therefore, an RPS built from the air-gap torque yields a more representative and robust signature of a faulty motor because it relies on a product of both currents and voltages/flux linkages of a monitored motor. That is why motor signatures were built from torque rather than current signals alone.

\section{SECTION VI.}

\section{Conclusion}

In this paper, a new technique for induction motor fault monitoring was presented. In this method, the air-gap torque profile was analyzed in order to identify the induction motor operating condition as either healthy or faulty, in which case the faulty condition 
represents the presence of one or more broken bars. The main advantages of this method are twofold. First, this technique, which was found to be robust, was trained with a dataset generated from a simulated motor, which avoided destructive tests to train this method. The datasets of the monitoring stage were obtained from experimental setups with actual motors of various designs. The fault classification accuracy was $100 \%$ at full load. Second, the novel torque normalization process of the monitoring stage normalizes the amplitude and frequency of the air gap torque signals during the monitoring stage to have similar amplitude and frequency when compared with the signatures from the training stage. As a result, this monitoring method which was trained for a simulated 2-hp induction motor can monitor the operating condition of actual induction motors with different levels of load torque and operating frequency, as well as design specifications, such as power rating (the case-study $5 \mathrm{hp}$ motor tested in the laboratory) and number of poles, which are different from the TSFE simulated motor used in the training stage. This is because of the fact that this novel torque normalization process leads to "generic" signatures which are independent of these parameters. The experimental results presented here evidenced the robustness and scalability of the method, which yielded good motor fault classification accuracy. Thus, this monitoring method based on the air-gap torque profile analysis can be a powerful tool for induction motor fault classification.

\section{References}

${ }^{1}$ A. M. da Silva, R. J. Povinelli, N. A. O. Demerdash, "Induction machine broken bar and stator short-circuit fault diagnostics based on three phase stator current envelopes", IEEE Trans. Ind. Electron., vol. 55, no. 3, pp. 1310-1318, Mar. 2008.

2J. Antonino-Daviu, S. Aviyente, E. G. Strangas, M. Riera-Guasp, "Scale invariant feature extraction algorithm for the automatic diagnosis of rotor asymmetries in induction motors", IEEE Trans. Ind. Inf., vol. 9, no. 1, pp. 100-108, Feb. 2013.

3P. Zhang, Y. Du, T. G. Habetler, B. Lu, "A survey of condition monitoring and protection methods for medium-voltage induction motors", IEEE Trans. Ind. Appl., vol. 47, no. 1, pp. 34-46, Jan.-Feb. 2011.

${ }^{4}$ S. M. A. Cruz, "An active-reactive power method for the diagnosis of rotor faults in three-phase induction motors operating under time-varying load conditions", IEEE Trans. Energy Conv., vol. 27, pp. 71-84, 2012.

5J. S. Hsu, "Monitoring of defects in induction motors through air-gap torque observation", IEEE Trans. Ind. Appl., vol. 31, no. 5, pp. 1016-1021, Sep.-Oct. 1995.

$6 \mathrm{~V}$. V. Thomas, K. Vasudevan, V. J. Kumar, "Implementation of online air-gap torque monitor for detection of squirrel cage rotor faults using TMS320C31", Proc. Int. Conf. Power Electron. Mach. Drives, pp. 128-132, 2002. 
NOT THE PUBLISHED VERSION; this is the author's final, peer-reviewed manuscript. The published version may be accessed by following the link in the citation at the bottom of the page.

7S. H. Kia, H. Henao, G. A. Capolino, "A high-resolution frequency estimation method for three-phase induction machine fault detection", IEEE Trans. Ind. Electron., vol. 54, no. 4, pp. 2305-2314, Aug. 2007.

8J. H. Jung, J. J. Lee, B. H. Kwon, "Online diagnosis of induction motors using MCSA", IEEE Trans. Ind. Electron., vol. 53, no. 6, pp. 1842-1852, Dec. 2006.

${ }^{9}$ A. Garcia-Perez, R. J. R. Troncoso, E. C. Yepez, R. A. O. Rios, "The application of high-resolution spectral analysis for identifying multiple combined faults in induction motors", IEEE Trans. Ind. Electron., vol. 58, no. 5, pp. 2002-2010, Oct. 2011.

${ }^{10} \mathrm{~V}$. N. Ghate, S. V. Dudul, "Cascade neural-network-based fault classifier for three-phase induction motor", IEEE Trans. Ind. Electron., vol. 58, no. 5, pp. 1555-1563, Oct. 2011.

11M. Eltabach, A. Charara, I. Zein, "A comparison of external and internal methods of signal spectral analysis for broken rotor bars detection in induction motors", IEEE Trans. Ind. Electron., vol. 51, no. 1, pp. 107-121, Feb. 2004.

${ }^{12}$ C. Kral, R. S. Wieser, F. Pirker, M. Schagginger, "Sequences of field-oriented control for the detection of faulty rotor bars in induction machines-the Vienna Monitoring Method", IEEE Trans. Ind. Electron., vol. 47, no. 5, pp. 1042-1050, Oct. 2000.

${ }^{13}$ A. Bellini, F. Filippetti, G. Franceschini, C. Tassoni, G. B. Kliman, "Quantitative evaluation of induction motor broken bars by means of electrical signature analysis", IEEE Trans. Ind. Appl., vol. 37, no. 5, pp. 1248-1255, Sep.-Oct. 2001.

140. Ondel, E. Boutleux, G. Clerc, "A method to detect broken bars in induction machine using pattern recognition techniques", IEEE Trans. Ind. Appl., vol. 42, no. 4, pp. 916-923, Jul.-Aug. 2006.

${ }^{15 T}$ T. W. Preston, A. B. J. Reece, P. S. Sangha, "Induction motor analysis by time-stepping techniques", IEEE Trans. Magn., vol. 24, no. 1, pp. 471-474, Jan. 1988.

16J. F. Bangura, A. O. Demerdash, "Diagnosis and characterization of effects of broken bars and connectors in squirrel-cage induction motors by a time-stepping coupled finite element-state space modeling approach", IEEE Trans. Energy Conv., vol. 14, no. 6, pp. 1167-1176, Dec. 1999.

17J. S. Hsu, A. M. A. Amin, "Torque calculations of current-source induction machines using the 1-2-0 coordinate system", IEEE Trans. Ind. Electron., vol. 37, no. 1, pp. 34-40, Feb. 1990.

18J. O. Ojo, V. Ostovic, T. A. Lipo, J. C. White, "Measurement and computation of starting torque pulsations of salient pole synchronous motors", IEEE Trans. Energy Conv., vol. 5, no. 1, pp. 176-182, Mar. 1990.

${ }^{19}$ A. M. da Silva, Induction motor fault diagnostic and monitoring methods, Marquette Univ., 2006.

20K. D. Hurst, T. G. Habetler, "Sensorless speed measurement using current harmonic spectral estimation in induction machine drives", IEEE Trans. Power Electron., vol. 11, no. 1, pp. 66-73, Feb. 1996.

21R. Blasco-Gimenez, G. M. Asher, M. Sumner, K. J. Bradley, "Performance of FFT-rotor slot harmonic speed detector for sensorless induction motor drives", Proc. IEEE Electric Power Applications, vol. 143, pp. 258-268, 1996.

22R. J. Povinelli, M. T. Johnson, A. C. Lindgren, J. Ye, "Time series classification using Gaussian mixture models of reconstructed phase spaces", IEEE Trans. Knowl. Data Eng., vol. 16, no. 6, pp. 779-783, Jun. 2004.

23H. D. I. Abarbanel, Analysis of Observed Chaotic Data, USA, NY, New York:Springer-Verlag, 1996.

IEEE Transactions on Industrial Informatics, Vol 9, No. 4 (November 2013): pg. 2274-2283. DOI. This article is (C Institute of Electrical and Electronics Engineers (IEEE) and permission has been granted for this version to appear in e-Publications@Marquette. Institute of Electrical and Electronics Engineers (IEEE) does not grant permission for this article to be further copied/distributed or hosted elsewhere without the express permission from Institute of Electrical and Electronics Engineers (IEEE). 
${ }^{24}$ M. T. Johnson, R. J. Povinelli, A. C. Lindgren, J. Ye, X. Liu, K. M. Indrebo, "Time-domain isolated phoneme classification using reconstructed phase spaces", IEEE Trans. Speech Audio Process., vol. 13, no. 4, pp. 458-466, Jul. 2005.

25F. Takens, "Detecting strange attractors in turbulence", Proc. Dynamical Syst. Turbulence, pp. 366-381, 1980.

26I. T. Nabney, NETLAB: Algorithms for Pattern Recognition, U.K., London:Springer, 2002.

27T. K. Moon, "The expectation-maximization algorithm", IEEE Signal Process. Mag., vol. 13, pp. 47-60, 1996.

28 “MAGSOFT A Commercially Available Time-Stepping Finite Element Software Package”, 2007.

${ }^{29}$ A. V. Oppenheim, R. W. Schafer, Discrete-Time Signal Processing, USA, NJ, Upper Saddle River:PrenticeHall, 1999.

30Z. Gao, T. Breikin, H. Wang, "Reliable observer-based control against sensor failures for systems with time delays in both state and input", IEEE Trans. Syst. Man Cybern. A, vol. 38, no. 5, pp. 10181029, Sep. 2008.

31Z. Gao, X. Dai, T. Breikin, H. Wang, "Novel parameter identification by using a high-gain observer with application to a gas turbine engine", IEEE Trans. Ind. Inf., vol. 4, no. 4, pp. 271-279, Nov. 2008. 